\title{
Mature Information Societies-a Matter of Expectations
}

\author{
Luciano Floridi ${ }^{1}$
}

We are so familiar with talk of "the information society" that we sometimes forget there is no such thing, but rather a multitude of societies, unalike from each other, some of which may qualify as information ones in different ways and degrees. So we should really speak of "information societies" without a "the" but with an "s", and ensure that our generalizations are not so generic as to apply to all of them, while obliterating any salient distinction. Just to be clear, there is always a level of abstraction at which something is like anything else: the moon is like your umbrella, which is like a pizza, because they are all singular objects that exist and look round, for example. The point is not being smug about one's own acrobatic equations ( $\mathrm{x}$ is like $\mathrm{y}$ which is like $\mathrm{z}$ ) but being critical in checking whether the level of abstraction at which the equation is drawn is the fruitful one to fulfil the purpose that one is pursuing. All this should clarify why, once we have many information societies that are all different from one another, it still makes sense to compare them in terms of relevant criteria and why, more specifically, it is important to understand what it means for an information society to be more or less mature than others.

Maturity is a matter of people's expectations, not just technological or economic development. Let me explain the difference with a concrete example first, and then an analogy.

The Organisation for Economic Cooperation and Development (OECD) collects many useful statistics that are useful for evaluating the stage of development of an information society. Because of the OECD's remit, they mostly refer to technological advancement. They are clustered around four main areas of development: broadband and telecom, Internet economy, consumer policy and digital government. Together, these areas may seem to provide a good snapshot of what it means for an information society to be mature. Indeed, this is a common approach. And yet it is far from satisfactory. Take the percentage of fibre connections in total broadband among countries reporting fibre subscribers (Fig. 1). Information updated to December 2014

Luciano Floridi

luciano.floridi@oii.ox.ac.uk

1 Oxford Internet Institute, University of Oxford, 1 St Giles, Oxford OX1 3JS, UK 


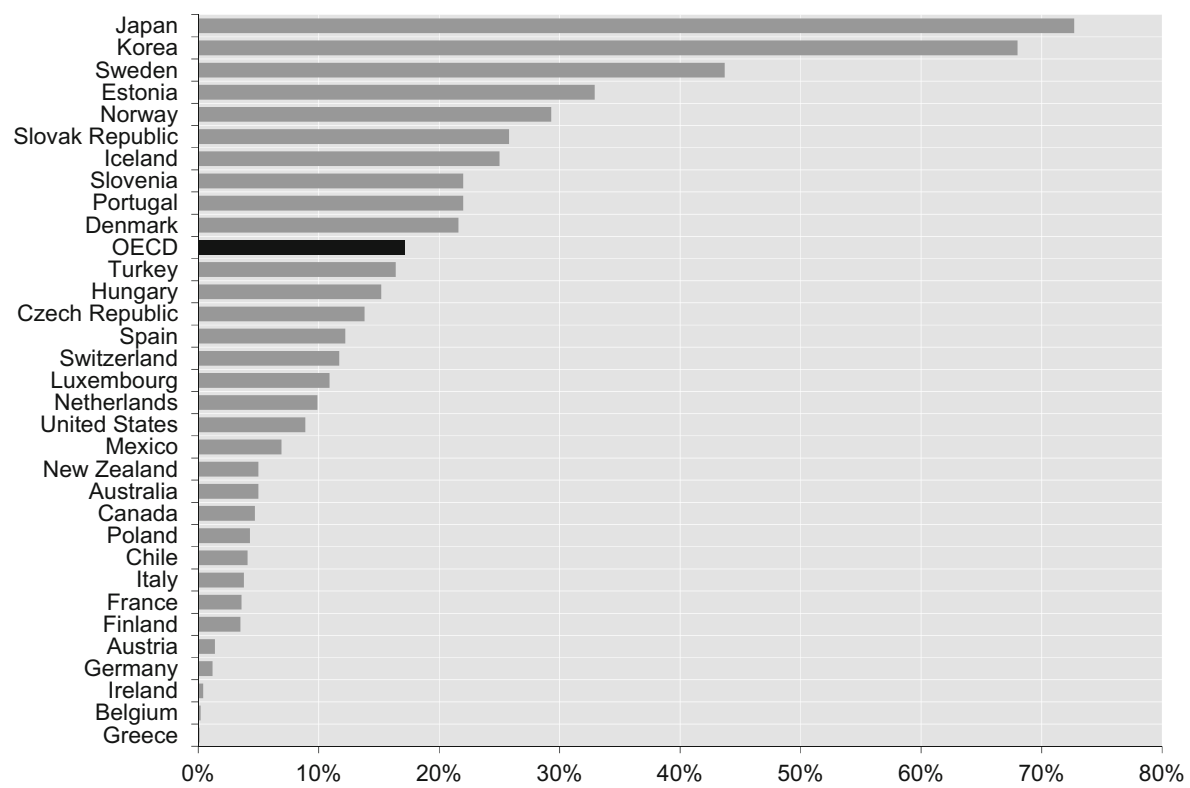

Fig. 1 Percentage of fibre connections in total broadband subscriptions, December 2014, source: http://www. oecd.org/internet/broadband/oecdbroadbandportal.htm

shows Japan, Korea and Sweden in the first three places, something that is not surprising, but it also ranks Turkey way above the Netherlands and the USA, while at the bottom we find countries such as Finland, Germany and Ireland, which one may consider rather mature information societies.

The percentage of fibre connections clearly does not provide a good criterion. Similar criticisms could be made of all the other statistical data provided by the OECD. The trouble with technological and economic approaches - think of connectivity, Internet penetration, number of computers per household, government open data projects, e-health services, usage of social media, ICT investment per capita and so forth - is that they capture only some conditions that facilitate the development of an information society. Such conditions are important, because they represent very helpful and significant affordances. Yet they are neither individually necessary nor altogether sufficient in themselves to explain in what sense and why an information society may be more mature than another. Something crucial is missing, namely people's expectations. Consider now the following analogy.

When you are in a hotel in Paris, you rightly expect the water in the bathroom to be drinkable because France is a "water mature society". In fact, you do not even think about it. There is no need for the hotel to advertise the safety of its water, nor for you to ask at the reception whether the water is drinkable. France is a "water mature society" not just because of its water system, but because people living there treat drinkable water as something ordinary, non-informative, a matter of fact that lies in the background. It is part of life, of what you implicitly and unreflectively expect water to be like in Paris. At the same time, we all know that drinkable water is not a trivial matter. According to the World Health Organization and UNICEF Joint Monitoring Programme, in 2015, nearly 700 million people-1 
in 10- did not have access to safe water. ${ }^{1}$ So if you take a more adventurous holiday in an unfamiliar place, your expectations change. It becomes normal to enquire whether it is safe even to brush your teeth with the water from the tap.

Clearly, expectations change contextually. They are a good way to gauge the maturity of the society in which one lives. The formula is simple: if the occurrence of a societal feature $\mathrm{F}$ is no longer informative but it is rather its absence that it is, then a society is $\mathrm{F}$ mature.

According to this interpretation, in some corners of the world, we are already living in mature information societies. In such corners, we expect as a matter of course to be able to order any kind of goods online, to pay for them digitally, to be able to exchange any sort of contents on the web, to search for any question and find any bit of information, to use services, stream entertainment and so forth, and all this $24 / 7$, seamlessly, quickly and reliably, without asking anymore whether it is possible, or being astonished that it is at all. We realise we live in a mature information society only when such expectations are unfulfilled.

Once we analyse information societies in terms of their members' unreflective and implicit expectations, comparable to having drinkable water in Paris, then we can switch from quantitative to qualitative assessments, and consider some significant consequences. Three seem to be more important than others, in no particular order of importance. $^{2}$

First, education. One can dismiss the myth of the "these days young people all know how to use [add your preferred technology here]". Young people are different from old people because of what they take for granted, i.e. their implicit expectations, not because of their innate skills, which, since Lamarck was wrong, are no better than the skills of any other member of the society in question. Children have no innate knowledge of how to use touch screens, but they are astonished if screens do not somehow respond to their touch, because that is their default expectation. Compare this to an automobile mature society. Precisely because it is not a matter of knowledge or skills but implicit assumptions and quiet expectations, Alice or Bob may live in an automobile mature society in which ordinary life is full of cars, parking spaces, traffic lights, petrol stations, motorways and so on, and all this working in some ordinary way, even if they do not know how to drive a car, have no idea how a car engine works, or how a car can be fixed. They may take the availability of public transport for granted, for example, and have no driving license. So not only the "young generation" has to learn, as any other generation, how to use specific technologies. It is also irrelevant whether it does, in order to understand whether such a generation lives in a mature information society. We rather need to check people's expectations. This is one of the many reasons why education is important: it makes one aware of one's own implicit assumptions and expectations, and of their justification, reasonableness and historical determination.

Second, understanding. Expectations may be blinding towards alternatives. Like in the water analogy, it is crucial to know what one may rightly expect from one's own society — drinkable water or good Internet connectivity - while knowing that this is

\footnotetext{
${ }^{1}$ Source: Progress on Drinking Water and Sanitation, 2015 Update and MDG Assessment, http://www.who. int/water_sanitation_health/monitoring/jmp-2015-update/en/

${ }^{2}$ For an overview see Floridi (2009)
} 
probably very far from, and way more privileged than, what millions of people enjoy in many other places. If you expect your bank to provide a scanning app to deposit cheques automatically online without walking into a branch and filling out a form, then you can rightly complain if it does not, while still being able to appreciate the fact that many people do not even have access to ATMs. More generally, a society implements a particular right increasingly well the more its breach becomes informative.

And finally, innovation. We saw that expectations determine what is ordinary and what is extraordinary, what is normal and what is abnormal. In short, they determine what is informative ${ }^{3}$ : being told that the water in your hotel in Paris is not drinkable (e.g. because of some work in progress) would be very informative, as would be having access to a high-speed Internet connection in a remote, beautiful island in the middle of nowhere. So innovation in a mature information society is culturally (mind, not technologically) more difficult to achieve than in an immature one. Because once people start taking for granted cars or TVs, for example, it does not really matter how much these technologies change, maturity has been reached, in terms of more of the same. Likewise, once people are used to living "onlife"-i.e. in that estuary represented by the mixing of online and off line experiences (Floridi 2014b) - more digital products, goods, services, or in general more affordances will not make that society even more mature.

Information societies are maturing all over the world. More will appear in the future. In terms of expectations, similarities therefore will increase. To paraphrase Tolstoy, all mature information societies are alike in terms of people's expectations; each immature society is immature in its own way. So the next stage in the development of information societies, be this in ten or a hundred years, will not be a further maturation of their inhabitants' expectations about their digital affordances, it will be an unprecedented and unforeseen transformation altogether, for which the digital will have become an implicitly expected backdrop. Hard to imagine, at a stage in which we are still going through our information revolution (Floridi (2014a)), but then history has a tendency to upgrade our imagination on a regular basis.

\section{References}

Floridi, L. (2008a). Artificial intelligence's new frontier: artificial companions and the fourth revolution. Metaphilosophy, 39(4/5), 651-655.

Floridi, L. (ed.), (2008b). Philosophy of computing and information: 5 questions. Automatic Press / VIP.

Floridi, L. (2009). The information society and its philosophy. The Information Society, 25(3), 153-158.

Floridi, L. (2011). A defence of constructionism: philosophy as conceptual engineering. Metaphilosophy, 42(3), 282-304.

Floridi, L. (2014a). The fourth revolution - how the infosphere is reshaping human reality. Oxford: Oxford University Press.

Floridi, L. (Ed.). (2014b). The onlife manifesto-being human in a hyperconnected era. New York: Springer.

\footnotetext{
${ }^{3}$ And hence what needs to be designed, see Floridi (2011) and for example Floridi (2008a). On different views about the philosophy of information see Floridi, L. (ed.) (2008b).
} 